\title{
Collaborative filtering content for parental control in mobile application chatting
}

\author{
Muhamad Ridhwan Bin Mohamad Razali, Suzana Ahmad, Norizan Mat Diah \\ Universiti Teknologi MARA (UiTM), Shah Alam, Selangor, Malaysia
}

\begin{tabular}{|c|c|}
\hline Article Info & ABSTRACT \\
\hline Article history: & Mobile phone is an important medium of communication for most people \\
\hline Received Apr 30, 2019 & $\begin{array}{l}\text { regardless their age. One of the most used mobile phone application is chat } \\
\text { application. Since mobile users are across different age groups from }\end{array}$ \\
\hline Revised Jun 14, 2019 & youngsters to senior citizen, each age level has their own ways or styles of \\
\hline Accepted Jul 16, 2019 & $\begin{array}{l}\text { communication when using mobile application chatting. Adult mostly used } \\
\text { proper syntax with complete sentences while youngsters normally use short }\end{array}$ \\
\hline Keywords: & $\begin{array}{l}\text { forms with incomplete sentences. In addition, improper communication } \\
\text { styles, usage of bad and inappropriate words has become a trend among }\end{array}$ \\
\hline Collaborative filtering & youngsters. This matter gives negative impact on the education system in a \\
\hline Content filtering & short-term and national language preservation in a long term. Hence, in this \\
\hline Education & mobile application chatting. This tool would be is an education material to \\
\hline Mobile application & younger generation users with subtle approach. Implementation of the tool is \\
\hline Online chatting & by adapting Collaborative Filtering approach with User-Based model which \\
\hline Parental guidance & $\begin{array}{l}\text { focusing on recommendation on similar interest between users. Collaborative } \\
\text { filtering content tool is functioning well during the functionality testing and it } \\
\text { is thriving as a mobile application chatting guidance. }\end{array}$ \\
\hline
\end{tabular}

Copyright $(0) 2019$ Institute of Advanced Engineering and Science. All rights reserved.

Corresponding Author:

Muhamad Ridhwan Bin Mohamad Razali, Faculty of Computer and Mathematical Science, Universiti Teknologi MARA (UiTM), Shah Alam, Selangor, Malaysia.

Email: muhamadridhwan48@gmail.com

\section{INTRODUCTION}

Communication is the process of sending and receiving messages through verbal or nonverbal means, including speech, or oral communication [1]. In other words, communication is the creation and exchange of meaning. Furthermore, it is a part of the daily activity for a normal human being. With technology advancement, people are able to communicate easily even in a distance. In addition, technology has introduced chat online in order to help people communicate with each other without meeting physically [2]. Unfortunately, bad language are widely used among the users especially teenagers. Yenala et. al (2018) defined an inappropriate or bad word as text that can cause any harm to sender and reader or show disrespectful to people or has an element of violent [3]. Yenala et. al (2018) also mentioned that conversations often led to the use of the inappropriate message [3]. This could be a menace to people, especially to an innocent kid. In addition, the trend now is short form typing and this thing could lead to grammar problem in school [4]. Due to this matter, most parents are worried with the improper usage of mobile application chatting for they do not have control over their children's communication activities [5].

Parental controls in mobile application chatting would be a big help to parents in order for them to monitor their children's chatting activities. The purpose of parental control is to assist parents in order to restrict certain content viewable by their children that may be inappropriate for their age. Chat online one of the social network sites that parents concern when their child's use internet [3]. This paper is divided into 
several sections, which are first, introduction; second, literature review; third technical aspects, fourth development and testing and lastly conclusion.

\section{LITERATURE REVIEW}

Most of the parents are worried if their immature children whose poses little judgement get involved with a negative influences like adult content in reading material, movies that show violent or even any games that promote gambling [2]. These are examples of technology negative impacts to the society. Among the influencing technology product is mobile phone. Society has been addicted to mobile phone and this has been worsening over the time[3-5]. Everyone in a family has a mobile phone and some own more than a phone. A lot of survey has been done that shows how addicted is the society to their mobile phone. Among addictive activities, that mobile phone provides is communicating and gaming $[3,6]$.

\subsection{Communication via mobile phone}

Mobile phone became one of the vital things in a human being's needs [6]. Since the technology had become a liaison between people in order to stay connecting despite long distance, WhatsApp became one of the top choices [7-9] for online chatting since it started in 2010. The most surprising thing was, users at young age had become the most hardcore user for this application [8]. Over the year, instant messaging like WhatsApp has become an important tool for many purposes including education and learning purposes. It also provide many impacts that is more beneficial to the users. However, negative impacts are also clearly affecting the society such as bad words usage, bad grammar adaptation and short forms trends. Nevertheless, this matter gives negative impact on the education system in a short-term and national preservation in a long term [9-11]. Therefore, parents should have a suitable platform or tools to control their children's communication channel. In order to do so, adaptation of collaborative filtering technique is very significant.

\subsection{Collaborative filtering}

Collaborative filtering $(\mathrm{CF})$ filters information by using the recommendations of other people. It is based on the idea that people who agreed in their evaluation of certain items in the past and the evaluations are likely to be agreed again in the future [12-15]. CF can be classified into Model and Memory based technique [2] which consists of two types, User-Based and an item-based algorithm. User- based basically have four levels, in the first level, user-to-user correlations are applied to find the most similar users to a target user. Second level is to collect items rated by a target user. Items that have already been obtained by the target user are than will be removed, leaving a set of candidate items. Third level is where a degree of preference score is generated to determine the likelihood of future actions by the target user for each candidate item. Lastly, respective prediction scores are ranked and a list of recommendations comprising the items with the highest ranks is generated.

In the user-based approach, the users will perform as the main role. If a certain majority of the users used same keyword, then they will be able to join into a group. Therefore, this mechanism is most suitable to handle decision making for users under complex scenario [16-17]. That's the reason why it also became the most important part of e-commerce and social media application as their need to give ease to customers to make a choice [15]. As a proof that Collaborative Filtering was a popular and efficient technique as recommender, Amazon and Netflix one of the examples that already adapted this technique to recommend the relevant product to their customers [18].

\subsection{Deep learning}

In CF, deep learning has been used in order to produce a good result in a recommendation [19]. Deep learning is a mechanism that use a structure of human brain as an artificial neural network so that computer application can has similar cognitive action like the normal human being. The purpose of deep learning is to increase the relevance of recommendations and to provide the results in a scalable way [20]. As [21] mentioned, deep learning was a crucial part in the recommendation system. Therefore, Collaborative Filtering also applied the same method using deep learning to train data in order to improve the result of the recommendation.

\subsection{Other research}

Research on other existing applications have been conducted. Table 1 shows comparison between eight existing applications that has similar objective which is to control the usage of words in application chatting. Four highlighted features in controling communication are: education material provided, blacklisted URLs/content filtering, parent involvement and monitoring social network acitivities. 
Table 1. Comparison between existing system and prototype

\begin{tabular}{|c|c|c|c|c|c|c|c|c|c|c|}
\hline Features & 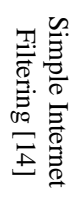 & 预 & 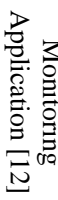 & 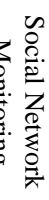 & 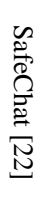 & $\begin{array}{l}5 \\
0 \\
\frac{0}{0} \\
0 \\
5 \\
0 \\
\stackrel{N}{\omega}\end{array}$ & $\begin{array}{l}\sum_{0} \\
1 \\
2 \\
0 \\
8 \\
0 \\
\frac{1}{N}\end{array}$ & $\begin{array}{l}3 \\
2 \\
2 \\
0 \\
\frac{2}{0} \\
\frac{0}{N} \\
\pm \\
\pm\end{array}$ & 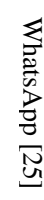 & 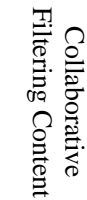 \\
\hline Education material & $x$ & $\checkmark$ & $x$ & & $x$ & $x$ & $\sqrt{ }$ & $\checkmark$ & & $\sqrt{ }$ \\
\hline Blacklisted URLs/Content Filtering & $\checkmark$ & $x$ & $x$ & & $x$ & $x$ & $\checkmark$ & $\checkmark$ & & $\checkmark$ \\
\hline Parent Involvement & $x$ & $\checkmark$ & $\checkmark$ & & $\checkmark$ & $\checkmark$ & $\checkmark$ & $x$ & & $\checkmark$ \\
\hline Monitor social network activities & $x$ & $x$ & $\checkmark$ & & $\checkmark$ & $\checkmark$ & $x$ & $x$ & & $\checkmark$ \\
\hline
\end{tabular}

Most of the existing system application listed has not provide education material except for FamilyLync, We-Choose and MediaKids. As for blacklisted URLs/Content Filtering feature, only Simple Internet Filtering, We-Choose and MediaKids have it. While, for parent involvement feature, most of the applications have it except for Simple Internet Filtering and MediaKids. Despite the fact that monitor social network activities is the most important features, only Social Network monitoring application, safeChat and Lock n'Lol has this feature.

SafeChat application is considered the most trusted application, and it is focusing on content privacy of messages. Therefore, it encrypt the chat content and make it accessible to the sender and receiver only. Additionally, SafeChat will block visible offensive content to keep children safe from negative elements using a Communication Service Provider (CSP). However, SafeChat does not include education material and blacklisted URLs/Content Filtering.

\section{TECHNICAL ASPECTS}

Collaborative Filtering Content is using User-based model to produces a recommendation list for object user according to the view of other users. The assumptions are if the ratings of some items rated by some users are similar, the rating of other items rated by these users will also be similar [15, 26, 27]. Collaborative Filtering Content recommendation system uses statistical techniques to search the nearest neighbors of the object user and then based on the item rating rated by the nearest neighbors to predict the item rating rated by the object user, and then produce corresponding recommendation list [28]. Collaborative Filtering content has component that uses a neighborhood-based algorithm. In neighborhood-based algorithms, a subset of users is choose based on their similarity to the active user, and weighted combination of their ratings is used to produce predictions for the active user [29, 30].

Table 2 shows the relationship between user and item in matrix form. In this scope, item (ia, ib, ic) was assumed as a word inserted by a user. For example, who use which item. In this scope, which user ever type a certain word. From this approach, we can know that users may have similar interest [27, 28]. Then, we can rely on past interest to predict other interest based on a nearest-neighbor concept.

Table 2. Example of user item matrix

\begin{tabular}{cccc}
\hline & ia & ib & ic \\
\hline User A & 2 & - & 1 \\
User B & - & 3 & 2 \\
User C & 2 & 1 & 1 \\
\hline
\end{tabular}

User-Based Collaborative Filtering Content will then analyze the entire data set of users and items to generate recommendation by determining users that have similar interests to the target one and then recommend an item to the next users. Calculation then proceeds by computing statistical metrics in a user-item matrix to measure the similarity between different rows and finding the nearest neighbors as shown in Figure 1. The User-Based similarities are calculated using row-wise. These neighbors are supposed to have similar interest with the target user. This will be followed by combining the neighbor's preferences and finding the top $\mathrm{N}$ items that have been rated highly by neighbors and not by the target user [26]. These $\mathrm{N}$ items will form the top $\mathrm{N}$ recommendations.

Finally, Collaborative methods that adapts in Collaborative Filtering Content work with the interaction matrix that can also be called rating matrix in the rare case when users provide explicit rating of items. The task of machine learning is to learn a function that predicts utility of items to each user. Therefore, Collaborative Filtering Content will be able to provide relevant word suggestion for the users. 


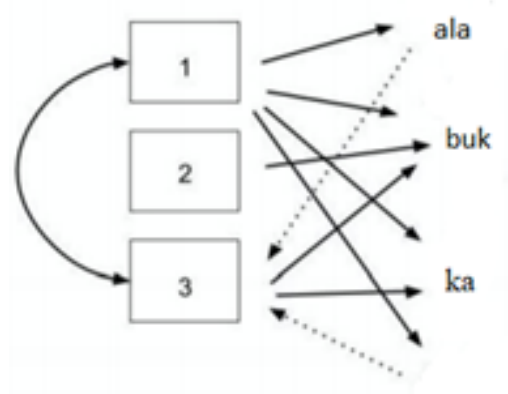

Figure 1. User-based model [28]

\section{DEVELOPMENT AND TESTING}

Collaborative Filtering Content is developed based of architecture shown in Figure 2, where text or wording will be recommended based on similar interest between users (parents and their children). System will differentiate two actors, which will be the one who supply training data (parents) and which will be the user who will receive the recommendations (children).

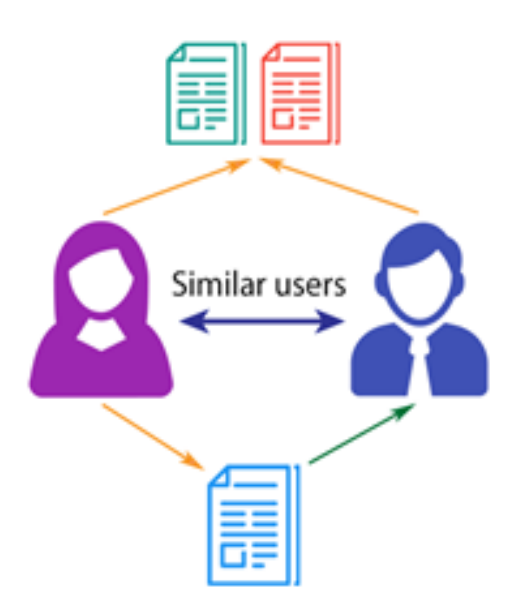

Figure 2. Collaborative filtering content's architecture

As for the flow for the Collaborative Filtering Content system, the flowchart is refer to Figure 3. The system flow starts with the chatting application. The users need to be in chat mode in order to type the messages. Then, the message that the user inserts will be treated as an input. In addition, parents side is contributing by giving a good input to get a good result of recommendations.

The input would be compared with a database whether it already exists or not. If not, the system would directly proceed to no suggestion. But, if the input matched with the data in the database, then it will be proceed with another checking whether the input is a bad word or not. If the input is a bad word, then it will end with no word suggestion whereas if it not a bad word, it will be process further. In this step, User Based CF algorithm take part and with that result, the system would display each word to the next users as recommendation word should be used when the users type any set of an alphabet. 


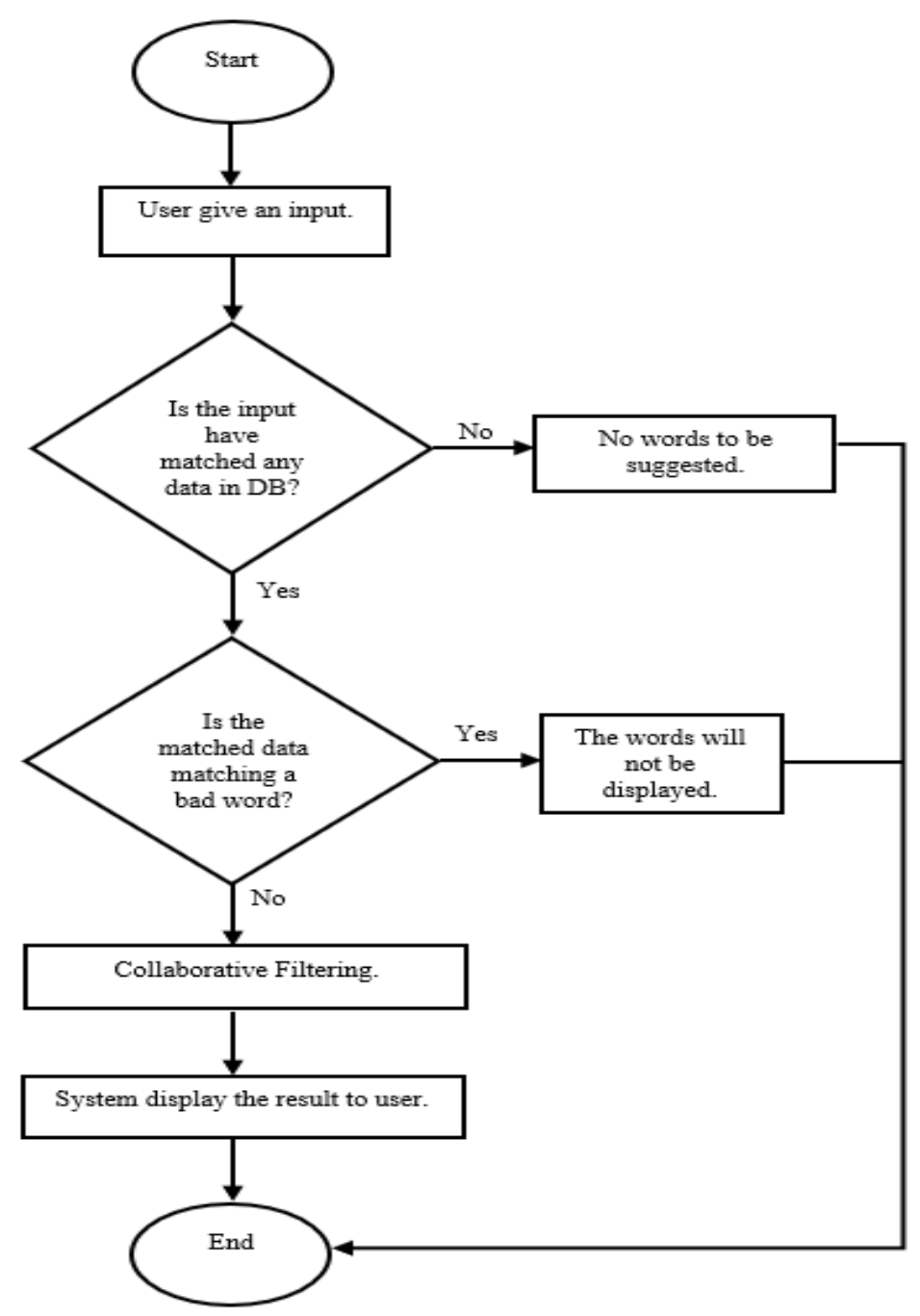

Figure 3. General flow collaborative filtering content system

Collaborative Filtering Content has been tested for its functionality. Figure 4 showed screen shots of the system. Collaborative Filtering Content is thriving as a mobile application chatting guidance. System is easy to use, where it will led the users to the main page of chat application that consists of the list of previous messages. In additions, there are add button in case users wants to add new messages. To make them easy to find previous chats, filter box was available at the top of the list of chats. Moreover, when users were typing, a keyboard would show up if they touch the text box. In the middle of they are typing some word, there are some suggestion words will be displayed at the top of their keyboard even though the words are still not finish typed. 


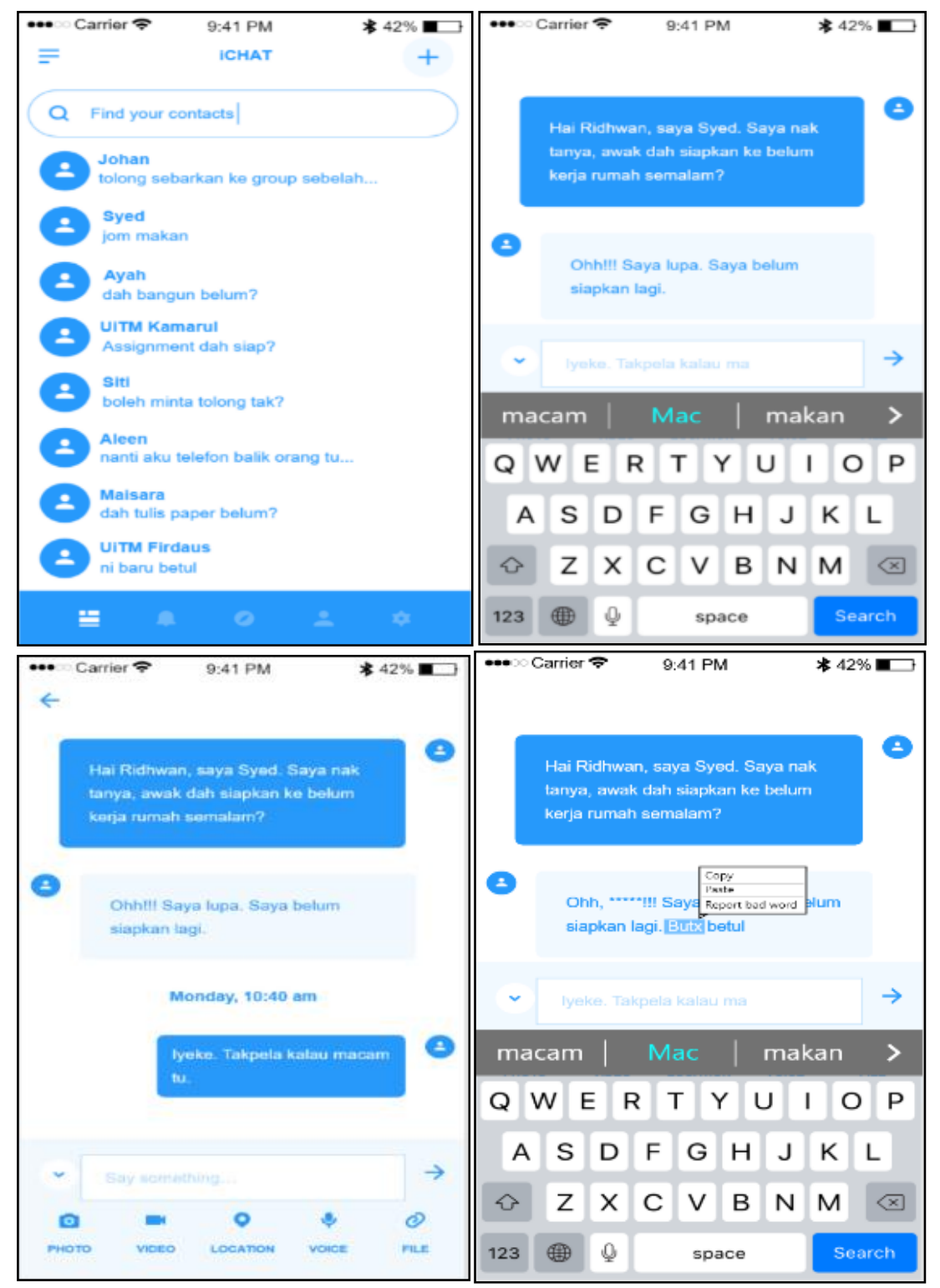

Figure 4. Screen shots of collaborative filtering contents

If the message has contained only a good word, then the sentence would be displayed as usual without censoring it. The words that listed out in the database as inappropriate word would be not displayed as a word but have been converted in other symbols to prevent users from seeing or know about that words. But, if bad word still displayed out as word and can be seen by any users, the users can report it by highlight that word and click "Report bad word" option as shown in Figure 4.

In Addition, user may also report or request for appropriate words that they prefer. System will be managed by administrator to monitor all the report request. Example of report is shown in Figure 5. The suggested words given to the users is based on previous users that frequently used the words. More frequent a has been used, the higher the probability of that word will become as the suggested word. 


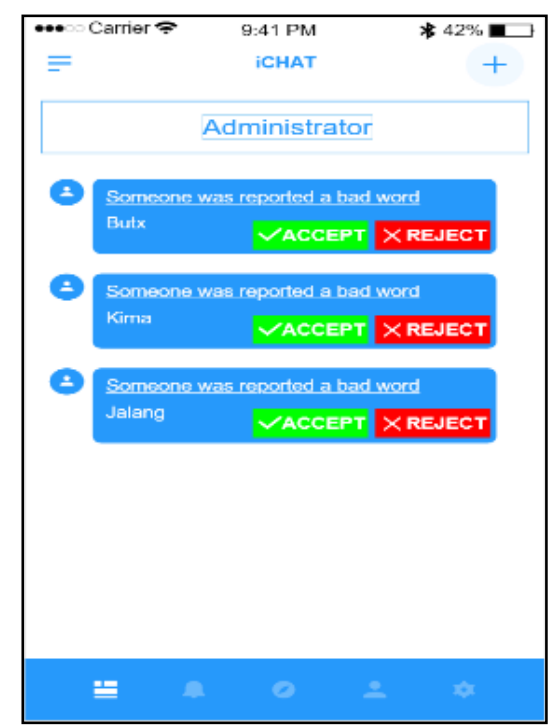

Figure 5. Admin approval report

\section{CONCLUSION}

Collaborative Filtering Content provides an alternative assistance for parents to monitor and guide their children in mobile application chatting. In addition, children will be able to learn a proper or suitable word to be used in their online conversation as well as in real life. Words that recommended will increase their word usage and vocabulary as well as improve their communication skills. Collaborative Filtering Content is one small step in providing a good IT community. Nevertheless, Collaborative Filtering Content architecture can be adapt by others similar application in the future.

\section{REFERENCES}

[1] Su X, Khoshgoftaar TM. "A survey of collaborative filtering techniques". Advances in artificial intelligence. 2009.

[2] Hashish Y, Bunt A, Young JE. "Involving children in content control: a collaborative and education-oriented content filtering approach". In Proceedings of the 32nd annual ACM conference on Human factors in computing systems ACM. Apr 26 (pp. 1797-1806). 2014.

[3] Fernández-Vilas A, Díaz-Redondo RP, Servia-Rodríguez S. "IPTV parental control: A collaborative model for the Social Web". Information Systems Frontiers. Oct 1;17(5):1161-76. 2015.

[4] Van Dijk CN, Van Witteloostuijn M, Vasić N, Avrutin S, Blom E. "The influence of texting language on grammar and executive functions in primary school children". PloS one. Mar 31;11(3):e0152409. 2016

[5] Aggarwal P, Tomar V, Kathuria A. "Comparing Content Based and Collaborative Filtering in Recommender Systems”. International Journal of New Technology and Research (IJNTR). April 2017; 3(4): 65-67.

[6] Koohi H, Kiani K. "User based Collaborative Filtering using fuzzy C-means". Measurement. Sep 1;91:134-9. 2016.

[7] Aziz, N. H. N., Haron, H., \& Harun, A. F. "Components of participatory engagement within E-learning community". Indonesian Journal of Electrical Engineering and Computer Science, 12(2), 556-561. 2018.

[8] Yahaya, C. K. H. C. K., Kassim, M., \& Husni, H. "Disruptive technology: The future of SMS technology". Indonesian Journal of Electrical Engineering and Computer Science, 11(2), 665-671. 2018.

[9] Tahir, Z. M., Haron, H., \& Singh, J. K. G. "Evolution of learning environment: A review of ubiquitous learning paradigm characteristics". Indonesian Journal of Electrical Engineering and Computer Science, 11(1), 175-181. 2018.

[10] Bouhnik D, Deshen M. "WhatsApp goes to school: Mobile instant messaging between teachers and students". Journal of Information Technology Education: Research. Jan 1; 13(1): 217-31. 2014.

[11] Montag C, Błaszkiewicz K, Sariyska R, Lachmann B, Andone I, Trendafilov B, Eibes M, Markowetz A. "Smartphone usage in the 21st century: who is active on WhatsApp?". BMC research notes. Dec; 8(1):331. 2015.

[12] P. Santisarun and S. Boonkrong, "Social network monitoring application for parents with children under thirteen," 2015 7th International Conference on Knowledge and Smart Technology (KST), Chonburi, 2015, pp. 75-80.

[13] Ko M, Choi S, Yang S, Lee J, Lee U. "FamiLync: facilitating participatory parental mediation of adolescents' smartphone use". In Proceedings of the 2015 ACM International Joint Conference on Pervasive and Ubiquitous Computing Sep 7 (pp. 867-878). 2015.

[14] Kamarudin AN, Ranaivo-Malançon B. "Simple internet filtering access for kids using naïve Bayes and blacklisted URLs". InInternational Knowledge Conference 2015. 
[15] J. Wei, J. He, K. Chen, Y. Zhou and Z. Tang, "Collaborative Filtering and Deep Learning Based Hybrid Recommendation for Cold Start Problem," 2016 IEEE 14th Intl Conf on Dependable, Autonomic and Secure Computing, 14th Intl Conf on Pervasive Intelligence and Computing, 2nd Intl Conf on Big Data Intelligence and Computing and Cyber Science and Technology Congress(DASC/PiCom/DataCom/CyberSciTech), Auckland, 2016, pp. 874-877.

[16] Jafarpour S, Burges CJ, Ritter A. "Filter, rank, and transfer the knowledge: Learning to chat". Advances in Ranking. Jul 12;10:2329-9290. 2010.

[17] Rashid AM, Albert I, Cosley D, Lam SK, McNee SM, Konstan JA, Riedl J. "Getting to know you: learning new user preferences in recommender systems". In Proceedings of the 7th international conference on Intelligent user interfaces Jan 13 (pp. 127-134). ACM. 2002.

[18] Wang H, Wang N, Yeung DY. "Collaborative deep learning for recommender systems". In Proceedings of the 21th ACM SIGKDD International Conference on Knowledge Discovery and Data Mining Aug 10 (pp. 1235-1244). 2015.

[19] Zhang S, Yao L, Sun A. "Deep learning based recommender system: A survey and new perspectives". arXiv preprint arXiv:1707.07435. Jul 24. 2017.

[20] Lee H, Lee J. "Scalable deep learning-based recommendation systems". ICT Express. Jun 22. 2018.

[21] Georgiev K, Nakov P. "A non-iid framework for collaborative filtering with restricted boltzmann machines". In International conference on machine learning Feb 13 (pp. 1148-1156). 2013.

[22] G. Fahrnberger, D. Nayak, V. S. Martha and S. Ramaswamy, "SafeChat: A tool to shield children's communication from explicit messages," 2014 14th International Conference on Innovations for Community Services (I4CS), Reims, 2014, pp. 80-86.

[23] Ko M, Choi S, Yatani K, Lee U. "Lock n'LoL: group-based limiting assistance app to mitigate smartphone distractions in group activities". In Proceedings of the 2016 CHI Conference on Human Factors in Computing Systems ACM. May 7 (pp. 998-1010). 2016.

[24] Poblet M, Teodoro E, González-Conejero J, Varela R, Casanovas P. “A co-regulatory approach to stay safe online: reporting inappropriate content with the MediaKids mobile app". Journal of Family Studies. May 4; 23(2): 180-97. 2017.

[25] Isha SK, Sharma S. "A Review on Perception of Usage-“WhatsApp"”. International Journal of Scientific Research in Computer Science, Engineering and Information Technology. 2018; 3(1): 1382-1393.

[26] Livingstone S, Mascheroni G, Dreier M, Chaudron S, Lagae K. "How parents of young children manage digital devices at home: The role of income, education and parental style". EU Kids Online, London, UK. 2015.

[27] Papagelis M, Plexousakis D. "Qualitative analysis of user-based and item-based prediction algorithms for recommendation agents”. Engineering Applications of Artificial Intelligence. Oct 1; 18(7): 781-9. 2005.

[28] Boström P, Filipsson M. "Comparison of User Based and Item Based Collaborative Filtering Recommendation Services”. Examensarbete Inom Teknik, Grundnivå, 15 HP, Stockholm, Sverige 2017. 2017.

[29] Thangavel SK, Thampi NS, Johnpaul CI. "Performance analysis of various recommendation algorithms using apache Hadoop and Mahout”. Int J Sci Eng Res. Dec;4(12):279-87. 2013.

[30] Al-Bashiri H, Abdulgabber MA, Romli A, Kahtan H. "An improved memory-based collaborative filtering method based on the TOPSIS technique”. PloS one. Oct 4;13(10):e0204434. 2018. 